University of Nebraska - Lincoln

DigitalCommons@University of Nebraska - Lincoln

Nebraska Cooperative Fish \& Wildlife Research Nebraska Cooperative Fish \& Wildlife Research Unit -- Staff Publications

2006

Predictors of introduction success in the South Florida avifauna

Craig R. Allen

University of Nebraska-Lincoln, callen3@unl.edu

Follow this and additional works at: https://digitalcommons.unl.edu/ncfwrustaff

Part of the Other Environmental Sciences Commons

Allen, Craig R., "Predictors of introduction success in the South Florida avifauna" (2006). Nebraska Cooperative Fish \& Wildlife Research Unit -- Staff Publications. 34.

https://digitalcommons.unl.edu/ncfwrustaff/34

This Article is brought to you for free and open access by the Nebraska Cooperative Fish \& Wildlife Research Unit at DigitalCommons@University of Nebraska - Lincoln. It has been accepted for inclusion in Nebraska Cooperative Fish \& Wildlife Research Unit -- Staff Publications by an authorized administrator of DigitalCommons@University of Nebraska - Lincoln. 


\title{
Predictors of introduction success in the South Florida avifauna
}

\author{
Craig R. Allen \\ USGS - Nebraska Cooperative Fish and Wildlife Research Unit, University of Nebraska, 111 Mussehl Hall, \\ 38th and Fair Streets, Lincoln, NE 68583-0711,USA (e-mail: allencr@unl.edu; fax: +402-472-2722) \\ Received 27 February 2004; accepted in revised form 15 November 2004
}

Key words: community assembly, cross-scale, Everglades, exotic species, introduced species, landscape structure, scale, textural-discontinuity hypothesis

\begin{abstract}
Biological invasions are an increasing global challenge, for which single-species studies and analyses focused on testing single hypotheses of causation in isolation are unlikely to provide much additional insight. Species interact with other species to create communities, which derive from species interactions and from the interactions of species with the scale specific elements of the landscape that provide suitable habitat and exploitable resources. I used logistic regression analysis to sort among potential intrinsic, community and landscape variables that theoretically influence introduction success. I utilized the avian fauna of the Everglades of South Florida, and the variables body mass, distance to nearest neighbor (in terms of body mass), year of introduction, presence of congeners, guild membership, continent of origin, distribution in a body mass aggregation or gap, and distance to body-mass aggregation edge (in terms of body mass). Two variables were significant predictors of introduction success. Introduced avian species whose body mass placed them nearer to a body-mass aggregation edge and further from their neighbor were more likely to become successfully established. This suggests that community interactions, and community level phenomena, may be better understood by explicitly incorporating scale.
\end{abstract}

\section{Introduction}

Analyses of the success of non-indigenous species introductions have largely focused on properties of the species, rather than the ecosystems that they invade (Forys and Allen 1999). Species traits may influence the success of invaders, but no specific traits lead to universal success. Investigations at the species-level have often produced conflicting predictions of invasion success (Kolar and Lodge 2001). Community-level investigations have placed biological invasions in the context of interactions among community members (Moulton and Pimm 1986) and have increased our understanding of invasions (Case 1990;
Drake et al. 1996). Deeper understanding of the factors leading to successful introductions and invasions may be enhanced by simultaneously examining the effect of intrinsic, community and landscape variables, because community membership is ultimately derived not only from species interactions, but also from the interactions of species with elements of the landscape that provide suitable habitat templates, available resources, and exploitable scales of resource distribution.

Some species traits often are associated with invasion and introduction success, notably high $r$, small body size, life span, geographic origin, and high mobility (Lodge 1993; Kolar and Lodge 
2001), although even these traits may mostly reflect historical contingency, are contradictory (for example small body size and life span), and may fail when rigorously tested (Forys and Allen 1999; Cassey 2001a). Most traits suggested as correlates of invasion success are actually associated with very few successful non-indigenous species. No individual-level trait alone predicts invasion success; those that seem to be correlated with invasiveness are general and vague, for example an association with disturbance.

Community-level interactions and characteristics of potentially invaded communities may be more predictive than intrinsic traits of species, or may interact with species traits. Community-level factors such as taxonomic relatedness and guild membership, saturation level of the community, and the presence of strong competitors or predators influence the success of potentially invasive or introduced species.

Decoupling the factors associated with a species ability to invade, the invasibility of species communities, and interactions between the above and landscape characteristics is difficult. For example, community membership is influenced by landscape processes affecting the spatial mosaic of habitats and the spatial and temporal scale of available ecological structure. Anthropogenic influences on landscapes, especially those that affect structuring processes (e.g., fire, hydrologic regimes, nutrient cycling) affect ecological structure and thus community membership. Ultimately, anthropogenic perturbation may change community membership by causing simultaneous events of invasion and extinction (Allen et al. 1999).

Few studies of biological invasions account for species that were introduced, but failed, because such data is rarely available, especially for continental faunas. For invasions (i.e., rapid species spread), it is not possible to know the potential, but unsuccessful, invaders; it is unclear what the species pool for potential invaders is. Investigations of invasions on oceanic islands offer somewhat firmer ground for the delineation of species pools, but even here there is controversy, and changing the species pool changes the outcome of investigations based on the extrapolation of a potential species pool (Cassey et al. 2004).

The continental avian fauna of the South Florida peninsula (Everglades sub-ecoregion) offers a unique opportunity for understanding the relative role of intrinsic, community and landscape factors influencing the success or failure of non-indigenous species introductions. The introduced fauna is well documented, including species that were introduced but subsequently failed. A large number of species $(>100)$ have been introduced, and a relatively large number of these have established breeding populations. Successful introduced and invasive species now constitute approximately $25 \%$ of the breeding bird fauna of South Florida (Forys and Allen 1999). With a reasonable level of confidence, it is possible to remove the effect of insufficient propagule size by considering only those species which were introduced in sufficient numbers for there to have been the possibility of successful establishment. I used the introduced avian fauna of South Florida to determine whether and which intrinsic, community, and landscape variables predict introduction success.

\section{Potential predictor variables}

Potential predictor variables were chosen either because they are often suggested as influencing introduction success or because they theoretically influence success. The potential list of variables is long, and I strived to include variables that were relevant to this system and fauna, that were available and that captured a broad range of the most accepted or likely predictors related to species traits, community interactions and landscape constraints. These variables are body mass, distance to nearest neighbor (in terms of body mass), year of introduction, presence of congeners, guild membership, geographic origin (continent) distribution in a body mass aggregation or gap, and distance to body-mass aggregation edge (in terms of body mass). These potential predictors of introduction success are described below.

\section{Intrinsic traits}

The variable body mass tested the prediction that small-bodied species are more likely to be successful invaders than larger species. Average body mass integrates a number of ecological 
attributes of a species, such as energy use, movement, home range size, life span and foraging behavior (Peters 1983), and has been repeatedly been suggested as a trait of invasive species (e.g., Cassey 2001a). The variable guild refers to the type of food consumed and the foraging strata (e.g., terrestrial, arboreal), utilizing the scheme described in Forys and Allen (1999). For analysis, I categorized guild as either "arboreal herbivore", "terrestrial herbivore", or other, because there were too few instances of other guild types. The influence of geographic origin was tested at the continental scale, and considered South America, Asia, and "other". The remaining five variables were associated with community or landscape interactions.

\section{Community-related variables}

Three variables tested theory associated with community-level predictors of invasion success: distance to nearest neighbor, year of introduction, and presence of congeners. All variables may be measures of competitive interactions among species. The variable nearest neighbor is the distance in $\log 10$ converted body mass to the nearest species in terms of mass, and represents a general measure of morphological similarity. In most principal component analyses investigating morphological overdispersion within an introduced species community, the first principal component is strongly associated with the overall size of a species. Morphological overdispersion has been documented in a large number of introduced bird avifaunas (e.g., Moulton and Pimm 1986; Moulton and Lockwood 1992). If competition among species within a community was regulated by morphological similarity (see also gap or aggregation membership, below), and body mass is a strong predictor of morphological similarity, one would expect successfully introduced species to be those that had body masses that were most dissimilar.

The variable year of introduction (the number of years before 2004) tested for a priority effect among introductions (Moulton 1993). A priority effect occurs when later introductions have a lower probability of success than earlier introductions. A body of evidence from the analysis of introduced bird communities on oceanic islands suggests that a priority effect exists (Moulton 1993; Brooke et al. 1995; Moulton et al. 1996). The results of various computer models suggests that a priority effect is expected in saturated communities (Case 1990; Drake et al. 1996), with the probability of successful invasion decreasing as a community becomes increasingly saturated. Community saturation theoretically occurs where all or most available niches are filled and all or most resources are optimally utilized. No analysis of priority effect in continental faunas has been previously conducted.

The "presence of congeners" variable was included because congeners are likely to compete most strongly because they are likely to be similar morphologically and ecologically (Moulton 1985). Members of disparate genera also may compete, but it is difficult to a priori determine the strength of interactions among non-congeneric community members. This categorical variable (congener present or absent) tested whether the presence of congeners influenced introduction success.

\section{Landscape-related variables}

The scale-specific effect of key ecological processes leads to a discontinuous distribution of ecological structure and pattern (Burrough 1981; O'Neill et al. 1991). The spatial and temporal distribution of ecological structure on a given landscape entrains attributes of animals (Holling 1992) both by sorting species and by providing a specific set of evolutionary opportunities and constraints. On the animal community level, this is expressed in discontinuous animal body mass distributions (Holling 1992), with distinct aggregations of masses separated by distinct and detectable gaps (Figure 1). The body mass structure in animal communities is similar across taxa within landscapes and between landscapes with similar structure (Holling et al. 1995; Restrepo et al. 1997). Animals within a particular body mass aggregation are believed to perceive and exploit the environment at the same or a similar range of scale, and thus aggregations compartmentalize species by their scale of environmental exploitation. Animals in different aggregations interact with their environment at different scales (Peterson et al. 1998). Processes such as 


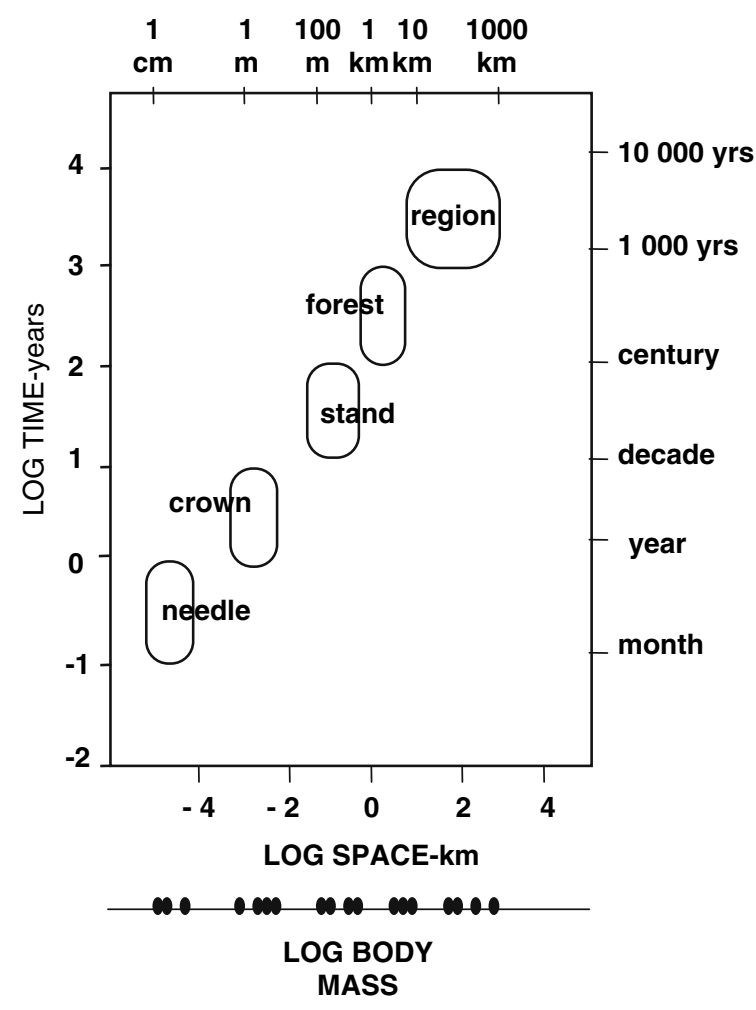

Figure 1. Space-time diagram showing the mapping of discontinuities and aggregations in vertebrate body mass distributions to the scale of dominant ecological structures. In this conceptual diagram, the five dominant structures are reflected in five aggregations of body masses in the body mass distribution of animals from this landscape.

community assembly, biological invasions and extinctions may be better understood by investigating interactions and phenomena within and across distinct ranges of scale. For example, one of the most commonly invoked predictors of invasion success, the link between invasion and disturbance, is too vague to be predictive, because the effect of disturbance is constrained by the scale of the disturbance relative to the body size of an animal (Allen et al. 1998). Allen et al. (1999) documented a non-random distribution, in terms of the body mass pattern, of non-indigenous and declining species for three taxonomic replicates (herpetofauna, birds, and mammals) from the South Florida sub-ecoregion and a similar pattern in non-indigenous birds and mammals from Mediterranean-climate Australia. Both non-indigenous and endangered species were located at the edge of body mass aggregations. Discontinuities were determined in the South Florida bird body mass distributions (described in methods), and this discontinuous structure used to determine two variables related to potential scale specific landscape related influences on introduction success.

Landscape related variables are distributions in a body mass aggregation or gap, and distance to body-mass aggregation edge. The variable distribution in a body mass aggregation or gap considers whether a species body mass places it into an aggregation of species or into a gap, where no species of similar body mass are found. If the body masses of successfully introduced species tended to place them in "gaps", this would suggest the importance of morphological dispersion, and would tend to result in a continuous distribution of body masses. It would also tend to place doubt upon the textural discontinuity hypothesis of Holling (1992). The variable distance to body-mass aggregation edge (in terms of $\log 10$ body mass) relates to the findings of Allen et al. (1999) that suggest that invasive species with average body masses that place them at the edge of body mass aggregation are most likely to be successful. Methods for the determination of discontinuities are described below. Other facets of the landscape may also affect the success of introduced species. These include adjacent land use (Smallwood 1994) and habitat-specific (local) community interactions and history (Case 1996), but it was not possible to test these effects in the context of this analysis, though they warrant further exploration.

\section{Materials and methods}

\section{Data}

Data on the avian species introduced into the South Florida Everglades sub-ecosystem (Bailey 1983; Broward, Collier, Dade, Hendry, Lee, Monroe, and Palm Beach counties) were compiled from published sources, primarily Stevenson and Anderson (1994) and Robertson and Wolfenden (1992). Additional information was gathered from researchers working with non-indigenous species in the region (E.A. Forys and M.P. Moulton, 
Table 1. Avian species introduced into the South Florida Everglades sub-ecosystem.

\begin{tabular}{|c|c|c|c|c|c|c|c|c|c|}
\hline Species & Success & Mass & Gap & Near & Edge & Yrbp & Congener & Origin & Guild \\
\hline Carpodacus mexicanus & 1 & 1.330 & 0 & 0.036 & 0.004 & 23 & 0 & NA & $\mathrm{HTe}$ \\
\hline Pyconotus jocosus & 1 & 1.438 & 0 & 0.065 & 0.006 & 45 & 0 & ASIA & HAr \\
\hline Melopsittacus undulates & 1 & 1.462 & 0 & 0.063 & 0.012 & 43 & 0 & AUS & HTe \\
\hline Paroaria coronata & 1 & 1.633 & 0 & 0.026 & 0.006 & 43 & 0 & SA & $\mathrm{HAr}$ \\
\hline Brotogeris versicolurus & 1 & 1.781 & 1 & 0.008 & 0.008 & 36 & 0 & SA & $\mathrm{HAr}$ \\
\hline Myiopsitta monachus & 1 & 2.004 & 1 & 0.020 & 0.020 & 31 & 0 & SA & $\mathrm{HAr}$ \\
\hline Aratinga weddellii & 1 & 2.033 & 1 & 0.004 & 0.004 & 19 & 1 & SA & HAr \\
\hline Acridotheres tristis & 1 & 2.041 & 0 & 0.004 & 0.014 & 20 & 1 & ASIA & OTe \\
\hline Psittacula krameri & 1 & 2.106 & 0 & 0.015 & 0.015 & 38 & 0 & ASIA/AFR & HAr \\
\hline Nandayus nenday & 1 & 2.107 & 0 & 0.013 & 0.013 & 34 & 0 & SA & HAr \\
\hline Zenaida asiatica & 1 & 2.185 & 0 & 0.014 & 0.006 & 44 & 1 & NA/SA & HTe \\
\hline Aratinga acuticaudata & 1 & 2.217 & 0 & 0.047 & 0.027 & 21 & 1 & $\mathrm{SA}$ & $\mathrm{HAr}$ \\
\hline Gracula religiosa & 1 & 2.283 & 0 & 0.049 & 0.012 & 35 & 0 & ASIA & $\mathrm{HAr}$ \\
\hline Aratinga mitrata & 1 & 2.301 & 0 & 0.031 & 0.005 & 18 & 0 & SA & $\mathrm{HAr}$ \\
\hline Aratinga erythrogenys & 1 & 2.301 & 0 & 0.031 & 0.005 & 20 & 1 & SA & $\mathrm{HAr}$ \\
\hline Amazona viridigenalis & 1 & 2.468 & 0 & 0.076 & 0.004 & 33 & 1 & SA & $\mathrm{HAr}$ \\
\hline Amazona amazonica & 1 & 2.529 & 0 & 0.049 & 0.002 & 30 & 0 & SA & $\mathrm{HAr}$ \\
\hline Ara severa & 1 & 2.540 & 0 & 0.037 & 0.009 & 26 & 0 & SA & HAr \\
\hline Columba livia & 1 & 2.550 & 0 & 0.028 & 0.007 & 203 & 1 & EUR & HTe \\
\hline Francolinus francolinus & 1 & 2.656 & 0 & 0.011 & 0.003 & 42 & 0 & ASIA & $\mathrm{HTe}$ \\
\hline Amazona oratrix & 1 & 2.699 & 0 & 0.054 & 0.004 & 31 & 1 & SA & $\mathrm{HAr}$ \\
\hline Dendrocygna biocolor & 1 & 2.851 & 0 & 0.004 & 0.002 & 53 & 0 & $\mathrm{NA} / \mathrm{SA}$ & HAq \\
\hline Dendrocygna autumnalis & 1 & 2.920 & 1 & 0.022 & 0.022 & 38 & 1 & $\mathrm{NA} / \mathrm{SA}$ & $\mathrm{HTe}^{\prime}$ \\
\hline Anas platyrhynchos & 1 & 3.034 & 0 & 0.017 & 0.001 & 144 & 1 & NA & HAq \\
\hline Cairina moschata & 1 & 3.392 & 1 & 0.014 & 0.014 & 36 & 0 & SA & HAq \\
\hline Pavo cristatus & 1 & 3.622 & 1 & 0.054 & 0.054 & 31 & 0 & ASIA & $\mathrm{HTe}^{*}$ \\
\hline Serinus mozambicus & 0 & 1.025 & 0 & 0.017 & 0.050 & 20 & 0 & AFR & HTe \\
\hline Lonchura punctulata & 0 & 1.134 & 1 & 0.022 & 0.022 & 39 & 0 & ASIA & $\mathrm{HTe}$ \\
\hline Padda oryzivora & 0 & 1.394 & 1 & 0.022 & 0.022 & 43 & 0 & ASIA & HTe \\
\hline Nymphicus hollandicus & 0 & 1.997 & 1 & 0.013 & 0.013 & 38 & 0 & AUS & HTe \\
\hline Acridotheres cristatellus & 0 & 2.053 & 0 & 0.002 & 0.016 & 20 & 1 & ASIA & $\mathrm{ITe}$ \\
\hline Eos bornea & 0 & 2.230 & 0 & 0.009 & 0.060 & 18 & 0 & ASIA & $\mathrm{HAr}$ \\
\hline Amazona ventralis & 0 & 2.380 & 1 & 0.012 & 0.012 & 28 & 0 & SA & HAr \\
\hline Amazona finschi & 0 & 2.480 & 0 & 0.001 & 0.087 & 28 & 0 & SA & HAr \\
\hline Callonetta leucophrys & 0 & 2.571 & 0 & 0.007 & 0.007 & 28 & 0 & SA & HAq \\
\hline Aramides cajanea & 0 & 2.599 & 1 & 0.021 & 0.021 & 38 & 0 & SA & OAq \\
\hline Amazona aestiva & 0 & 2.602 & 1 & 0.025 & 0.025 & 24 & 0 & SA & HAr \\
\hline Amazona autumnalis & 0 & 2.619 & 1 & 0.026 & 0.026 & 23 & 0 & SA & HAr \\
\hline Amazona auropalliata & 0 & 2.681 & 0 & 0.013 & 0.036 & 21 & 0 & SA & $\mathrm{HAr}$ \\
\hline Gallus gallus & 0 & 2.827 & 0 & 0.007 & 0.028 & 37 & 0 & ASIA & $\mathrm{HTe}$ \\
\hline Buteogallus urubitinga & 0 & 2.998 & 0 & 0.001 & 0.053 & 30 & 0 & SA & CAe \\
\hline Numida meleagris & 0 & 3.114 & 1 & 0.053 & 0.053 & 58 & 0 & AFR & $\mathrm{HTe}$ \\
\hline Alopochen aigyptiaca & 0 & 3.270 & 0 & 0.048 & 0.108 & 38 & 0 & AFR & HAq \\
\hline Anser cygnoides & 0 & 3.498 & 1 & 0.120 & 0.120 & 17 & 0 & ASIA & HAq \\
\hline Anser anser & 0 & 3.520 & 1 & 0.141 & 0.141 & 15 & 0 & EUR & HAq \\
\hline Cygnus olor & 0 & 4.031 & 1 & 0.267 & 0.267 & 30 & 0 & EUR/ASIA & HAq \\
\hline
\end{tabular}

Success $=$ success or failure of introduction, $0=$ failure, $1=$ success. Mass $=\log (10)$ converted mass, in grams. Gap $=$ whether an introduced species body mass places it in an aggregation of species or a gap, $0=$ in an aggregation of species, $1=$ between aggregations. Near $=$ distance to nearest neighbor in terms of $\log (10)$ body mass. Edge $=$ distance to nearest aggregation defining "edge" species in terms of $\log (10)$ body mass units. Yrbp = number of years before present (2004) that a species was introduced. Congener $=$ presence or absence of native or successfully introduced species of the same genus at time on $n$th species introduction, $0=$ no congener present, $1=$ congener present. Origin $=$ the continent of origin $(\mathrm{NA}=$ North America, SA $=$ South America, AUS $=$ Australia, AFR = Africa, EUR = Europe $)$. Guild $=$ foraging strata and diet $(\mathrm{H}=$ herbivore, $0=$ omnivore, $\mathrm{I}=$ insectivore, $\mathrm{C}=$ carnivore; $\mathrm{Te}=$ terrestrial, $\mathrm{Ar}=$ arboreal, $\mathrm{Aq}=$ aquatic, $\mathrm{Ae}=$ aireal). 
personal communication), and from the Florida Biodiversity Project (http://www. wec.ufl.edu/ coop/GAP/). Because unsuccessful invasive species cannot be determined with any certainty, I used data only for introductions, both purposeful and inadvertent. Twenty-six species were considered to have been successfully introduced and established (Table 1).

I eliminated unsuccessful species introduced with little or no possibility of establishment due to an insufficient propagule. Because propagule size was not directly available, I considered only those species that were present for $>5$ years (Roberson and Woolfenden 1992; Stevenson and Anderson 1994) and that were known or suspected to have bred (Breeding Bird Atlas; Kale et al. 1992; Stevenson and Anderson 1994) in South Florida and/or where at least 5 individuals were known to have been released (the binomial probability of all individuals being of the same sex approaches 0.05 when $n=5$, assuming equal probability of selecting a male or female and random selection). This conservative interpretation led to the inclusion of 20 species introduced, but not established, in South Florida. Species body mass was determined from Dunning (1993). Year of introduction was determined primarily from Stevenson and Anderson (1994).

To determine the variables distribution in a body mass aggregation or gap, and distance to body-mass aggregation edge, it was first necessary to determine the body mass structure, and the location of discontinuities, in the body mass distribution of the native birds of South Florida. To determine body mass structure, that is, the location of body mass aggregations and gaps in the body mass distribution of the native birds of South Florida, I used computer simulations to locate significant discontinuities in the body mass distribution, and cluster analysis (SAS Inc. 1989) to confirm my interpretation (Allen and Holling 2001). Simulations compared actual body mass data with a null distribution constructed from a kernel density estimate that smoothes the observed data into a continuous unimodal null (Silverman 1981). Gaps are defined as areas between successive body masses that significantly exceed the discontinuities generated by the continuous null distribution (Restrepo et al. 1997). Significance of gaps is determined by comparing the body mass difference between species in a ranked distribution with the values generated by sampling the null distribution 10,000 times. Unusually large values are considered significant. Restrepo et al. (1997) maintained constant alpha levels when performing analyses, whereas Allen et al. (1999) maintained constant power, the approach used here. A species aggregation was a grouping of three or more species. Each species aggregation is defined by two endpoint species and their respective body masses. Thus, the variable distance to body mass aggregation edge is measured as the distance in body mass units to the nearest body mass aggregation defining (endpoint) species. It is assumed that species within an aggregation perceive and exploit their environment at the same ecological scale, which differs from species in other body mass aggregations (Peterson et al. 1998; Allen et al. 1999). Intrinsic, community and landscape hypotheses related to patterns in body mass distributions are shown in Figure 2.

\section{Analysis}

I used logistic regression (SAS Institute Inc. 1989) to determine significant predictors of introduction success. The binary response variable was whether or not a species was classified as successful. The independent variables are listed and discussed above. The variables mass, near and edge were rescaled prior to analysis (Menard 1995). I used backward selection logistic regression (Menard 1995), which provides an appropriate method for estimating a multiple regression when the dependent variable is binary (i.e., 0 or 1). I set the significance level of independent variables to stay in the model at 0.1 .

\section{Results}

The body mass distribution of the birds of South Florida was discontinuously distributed (Figure 3; Allen et al. 1999; Forys and Allen 2002). The eight variable logistic analysis model was untenable due to quasi complete separation (no maximum likelihood estimate exists) caused by inclusion of the variable congener. In only one case of unsuccessful introduction was a congener 


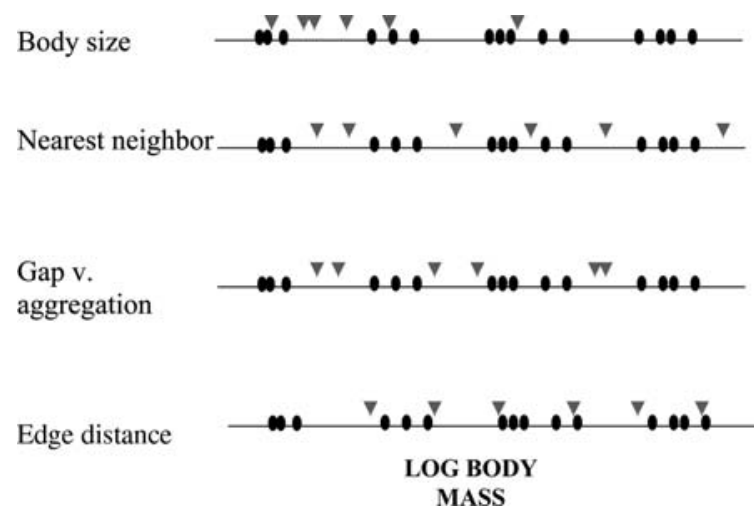

Figure 2. The four potential predictors of introduction success based on body size distributions. Species of an ecosystem are shown as circles along a body mass axis, and successful introduced species as downward pointing triangles. There are four aggregations of species shown. In "body size", introduction success is related to the size of an introduced species. Here, smaller species are successful, but the opposite could be true. In "nearest neighbor", species with body masses most dissimilar to species already present are successful. In "gap v. aggregation" species position in a body mass gap or aggregation predicts success. Here, gap species are successful, but the opposite could be true. In "edge distance" species closer to the edge of a body mass aggregation are most likely to be successful, but the opposite could be true.

present at the time of introduction. Thus, the variable congener was removed. The backward selection process selected a significant $(P<$ $0.0001)$ two variable model (Table 2 ). The significant variables were distance to body-mass aggregation edge $(P=0.023)$, and distance to nearest neighbor $(P=0.067)$. The adjusted $R^{2}$ value was 0.71 and Hosmer and Lemeshow goodness-of-fit test statistic $(4.05, P=0.774)$ indicated that the null hypothesis that the model fits the data well cannot be rejected. The final backward selection model took the form:

$$
\begin{aligned}
\text { Logit }(\text { success })= & 1.042 \times \text { intercept }+1.61 \\
& \times \text { near }-0.204 \times \text { edge }
\end{aligned}
$$

Success was more likely where a species' body mass placed it more distant from its neighbor and closer to the edge of an aggregation. Observed concordance in responses was $>93 \%$. The median distance to a body mass aggregation edge for unsuccessfully introduced species (0.0318) was five times greater than that of successfully introduced species (0.0068).

\section{Discussion}

The search for predictors of introduction success has been hampered by extrapolation from single species studies, the adherence to one or another competing hypothesis of single causation, and confusion of contingency with causation. Multiple causes are responsible for the success of invasive species and these include introduction effort (Griffith et al. 1989; Cassey 2001b), anthropogenic and other landscape changes (Allen et al. 1999), intrinsic traits of invasive species (Lodge 1993; Kolar and Lodge 2001), community properties such as saturation, and the scale of perturbation and resource distribution within and across scales.

Propagule size has an obvious influence on introduction success (Veltman et al. 1996). Except with parthenogenic species or in the case of a pregnant female, a propagule of one has zero possibility of establishment. The relationship between propagule size and successful establishment may asymptote quickly (Griffith et al. 1989; Pimm 1991). I attempted to eliminate the effect of propagule size, and consider only those species introduced with a minimally sufficient propagule. However, human effort may affect introduction success in other ways, by, for example, conducting multiple releases or releases at multiple sites (Veltman et al. 1996), and I was unable to test for those effects.

A focus on intrinsic traits alone is too narrow to provide a reasonable model for understanding introduction success. Intrinsic traits of species did not account for successful introductions in the South Florida vertebrate fauna. Forys and Allen (1999) used the entire vertebrate fauna of the Everglades ecosystem to test the hypotheses that successful introduced and invasive species were more likely to be small and dietary generalists (wide potential niche) and failed to support either hypothesis, nor were invasive species replacing declining species on the basis of niche. This analysis confirms that body mass per se is not a significant predictor of introduction success.

I found two significant predictors of introduction success, one related to the distribution of resources within and across scales and the other to interspecific interactions. Allen et al. (1999) 


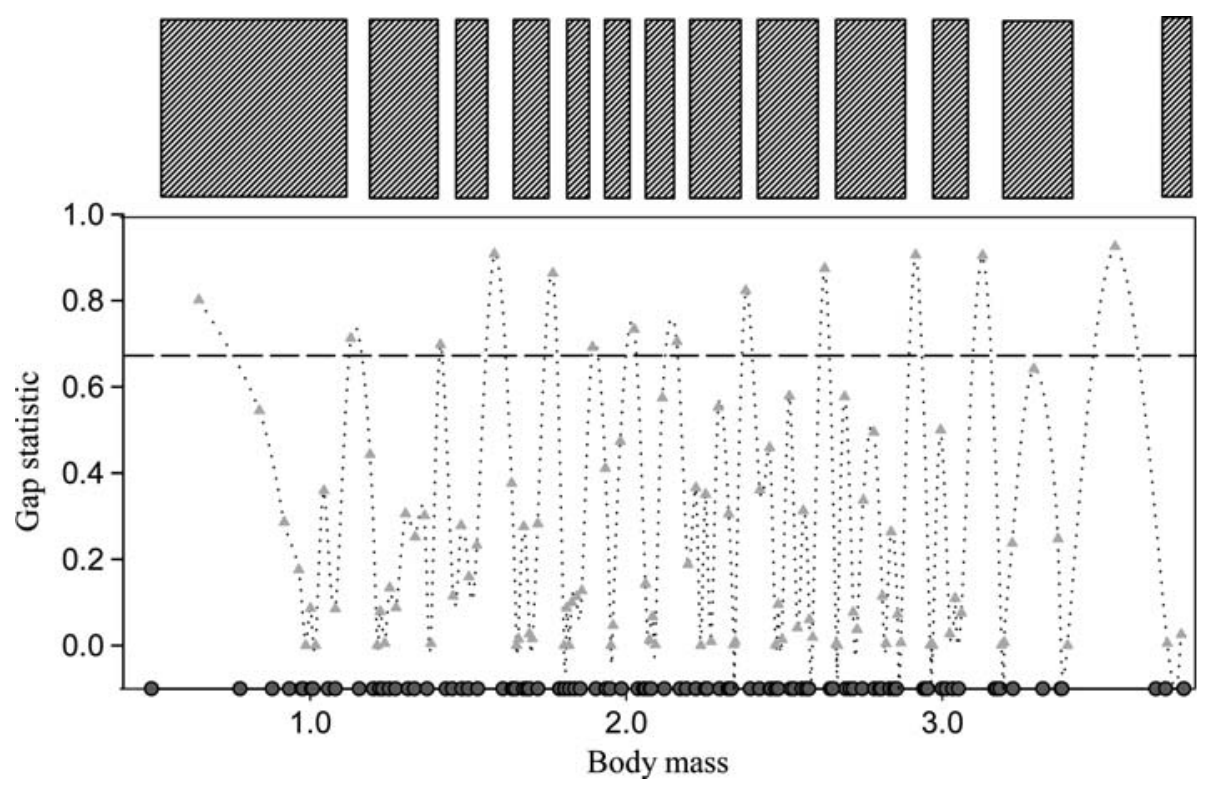

Figure 3. Gap statistic and body mass pattern for the Everglades ecosystem birds. Significant discontinuities in the body mass distribution were determined with computer simulations and confirmed with cluster analysis. Simulations compared actual body mass data with a null distribution constructed from a kernel density estimate that smoothes the observed data into a continuous unimodal null. Gaps were defined as areas between successive body masses that significantly exceeded the discontinuities generated by the continuous null distribution. A species aggregation (shaded) is defined as a grouping of three or more species with body masses not exceeding the expectation of the null distribution. Each species aggregation is defined by two endpoint species and their respective body masses. All data is presented in the lower graphic, while the upper graphic displays a stylized version of the body mass pattern. Modified from Allen et al. 1999.

Table 2. Backward selection logistic regression model after elimination of non-significant predictor variables $(P=0.0001)$.

\begin{tabular}{llllll}
\hline Variable & Parameter estimate & Standard error & Wald chi-square & $P$-value & Odds ratio \\
\hline Intercept & 1.042 & 0.766 & 1.851 & 0.174 & NA \\
Neighbor distance & 1.605 & 0.877 & 3.347 & 0.067 & 4.976 \\
Edge distance & -0.204 & 0.090 & 5.181 & 0.023 & 0.815 \\
\hline
\end{tabular}

Neighbor distance $=$ distance to nearest neighbor in terms of $\log (10)$ body mass units. Edge distance $=$ distance to nearest aggregation defining "edge" species in terms of $\log (10)$ body mass units.

documented that successful non-indigenous species (both introduced and invasive) occurred more often than expected at the edge of body mass aggregations, and a similar relationship for nomadic species (Allen and Saunders 2002). These results extend those by accounting for unsuccessful species and incorporating other variables. Allen et al. (1999) speculated that the edge of body mass aggregations represent scale breaks, zones of transition in between scales of available resources. Holling (1992) and Allen et al. (1999) suggested that resources are distributed discontinuously in space and time, and that there are abrupt shifts between ranges of scales. Theory suggests that body mass aggregations are a response to resource availability at that scale, and the pattern of aggregations and discontinuities in body mass distributions reflects the distribution of resources within and across scales.

Discontinuous body mass patterns have now been documented in many systems (e.g., Holling 1992; Restrepo et al. 1997; Lambert and Holling 1998; Allen et al. 1999; Raffaelli et al. 2000; Havlicek and Carpenter 2001). Analyses by 
Raffaelli et al. (2000), Havlicek and Carpenter (2001) and Forys and Allen (2002) suggest that body mass structure is conservative, robust to perturbations and large turnover in species composition. The association of invasiveness and decline (Allen et al. 1999, this paper) and nomadism (Allen and Saunders 2002) with discontinuities in body mass distributions, provides compelling evidence that discontinuities are biologically important.

Landscape pattern across different scales are described by different scaling relationships (Krummel et al. 1987), and the analysis of the relationship between species richness and spatial scale has demonstrated the existence of different scaling relationships at different scales (Crawley and Harral 2001). In between scales there are sharp breaks between these scaling regimes (Krummel et al. 1987; Crawley and Harral 2001).

A critical determinant of vertebrate community structure may be the landscape with which a species interacts, and specifically the scale-specific and discontinuous distribution of resources within and across scales. This leads to discontinuous body mass distribution in vertebrate communities, the segregation of communities into distinct groupings of species, based on body mass, that operate at similar ranges of scale (Holling 1992). Aggregations of species with similar body masses are strongly interacting, with the result that species exploiting the same resource in a similar way tend not to occur in the same body mass aggregation. Potentially strong competitors (e.g., members of the same functional guild) tend to coexist by exploiting their environment at different scales (Peterson et al. 1998). Congeners that might otherwise be expected to strongly interact on the basis of phylogenetic, morphological or ecological similarity, may interact very little if they exploit the environment at different ranges of scale (Peterson et al. 1998). Within a scale, competition for resources is expected to be strong, and the propensity for successfully introduced species to have body masses that are more distant from neighbors supports that contention. However, this does not fill in the gaps in the body mass distributions; structure in body mass distributions is conserved even with large species turnover (Havlicek and Carpenter 2001; Forys and Allen 2002). Thus, morphological overdispersion of non-congeners seems to be most pronounced within ranges of scales.

If body mass structure reflects landscape structure at different scales, the analysis of body mass distributions is a powerful tool for community ecology and invasion biology, and provides a strong link between community and landscape ecology. Scaling species interactions may provide clearer insight into phenomena such as biological invasions and extinctions, and the landscape and community-level processes driving them.

\section{Acknowledgements}

An earlier version of this manuscript was improved by comments from A. R. Johnson, M. P. Moulton, G. D. Peterson and B. Weeks. The Arthur Marshall Ecology Laboratory provided stimulating discussions of these ideas; especially stimulating was R. Yorque. The Nebraska Cooperative Fish and Wildlife Research Unit is jointly supported by a cooperative agreement among the USGS/BRD, the Game and Parks Commission, the University of Nebraska, and the Wildlife Management Institute. Support for this research was provided by the James S. McDonnel Foundation - 21st Century Research Award, Studying Complex Systems.

\section{References}

Allen CR and Holling CS (2001) Cross-scale morphology. In: El-Shaarawi AG and Piegorsch WW (eds) Encyclopedia of Environmetrics, pp 450-451. John Wiley and Sons, Chichester, UK

Allen CR and Saunders DA (2002) Variability between scales: predictors of nomadism in birds of an Australian Mediterranean-climate ecosystem. Ecosystems 5: 348-359

Allen CR, Lutz RS and Demarais S (1998) Ecological effects of the invasive non-indigenous ant, Solenopsis invicta, on native vertebrates: the wheels on the bus. Transactions of the 63rd North American Wildlife and Natural Resources Conference 63: $56-65$

Allen CR, Forys EA and Holling CS (1999) Body mass patterns predict invasions and extinctions in transforming landscapes. Ecosystems 2: 114-121

Bailey RG (1983) Delineation of ecosystem regions. Environmental Management 7: 365-373

Brooke RK, Lockwood JL and Moulton MP (1995) Patterns of success in passeriform bird introductions on Saint Helena. Oecologia 103: 337-342 
Burrough PA (1981) Fractal dimensions of landscapes and other environmental data. Nature 294: 240-242

Case TJ (1990) Invasion resistance arises in strongly interacting species-rich model competition communities. Proceedings of the National Academy of Sciences of the USA 87: 9610-9614

Case TJ (1996) Global patterns in the establishment and distribution of exotic birds. Biological Conservation 78: 6996

Cassey P (2001a) Are there body size implications for the success of globally introduced land birds?. Ecography 24: 413-420

Cassey P (2001b) Determining variation in the success of New Zealand land birds. Global Ecology and Biogeography 10: $161-172$

Cassey P, Blackburn TM, Jones KE and Lockwood JL (2004) Mistakes in the analysis of exotic species establishment: source pool designation and correlates of introduction success among parrots (Aves: Psittaciformes) of the world. Journal of Biogeography 31: 277-284

Crawley MJ and Harral JE (2001) Scale dependence in plant biodiversity. Science 291: 864-868

Drake JA, Huxel GR and Hewitt CL (1996) Microcosms as models for generating and testing community theory. Ecology 77: $670-677$

Dunning JB, Jr (1993) CRC Handbook of Avian Body Masses CRC Press, Ann Arbor, Michigan, USA

Forys EA and Allen CR (1999) Biological invasions and deletions: community change in South Florida. Biological Conservation 87: 341-347

Forys EA and Allen CR (2002) Functional group change within and across scales following invasions and extinctions in the Everglades ecosystem. Ecosystems 5: 339-347

Griffith B, Scott JM, Carpenter JW and Reed C (1989) Translocation as a species conservation tool: status and strategy. Science 245: 477-480

Havlicek T and Carpenter SR (2001) Pelagic size distributions in lakes: are they discontinuous? Limnology and Oceanography 46: 1021-1033

Holling CS (1992) Cross-scale morphology, geometry, and dynamics of ecosystems. Ecological Monographs 62: 447-502

Holling CS, Schindler DW, Walker BW and Roughgarden J (1995) Biodiversity in the functioning of ecosystems: an ecological synthesis. In: Perrings C, Mäler CKG, Folke C, Holling CS and Jansson BO (eds) Biodiversity Loss: Economic and Ecological Issues, pp 44-83. Cambridge University Press, New York, USA

Kale HW II, Pranty B, Stith BM and Biggs CW (1992) The atlas of breeding birds of Florida. Nongame Wildlife Program, Final report. Florida Game and Freshwater Fish Commission, Tallahassee, Florida, USA

Kolar CS and Lodge DM (2001) Progress in invasion biology: predicting invaders. Trends in Ecology and Evolution 16: 199-204

Krummel JR, Gardner RH, Sugihara G, O'Neill RV and Coleman PR (1987) Landscape patterns in a disturbed environment. Oikos 48: 321-324

Lambert WD and Holling CS (1998) Causes of ecosystem transformation at the end of the Pleistocene: evidence from mammal body mass distributions. Ecosystems 1: 157-175
Lodge DM (1993) Biological invasions: lessons for ecology. Trends in Ecology and Evolution 8: 133-137

Menard S (1995) Applied Logistic Regression Analysis. Sage University Paper series on Quantitative Applications in the Social Sciences, 07-106. Thousand Oaks, California, USA

Moulton MP (1985) Morphological similarity and coexistence of congeners: an experimental test with introduced Hawaiian birds. Oikos 44: 301-305

Moulton MP (1993) The all-or-none pattern in introduced Hawaiian passerines: the role of competition sustained. American Naturalist 141: 301-305

Moulton MP and Lockwood JL (1992) Morphological dispersion of introduced Hawaiian finches: evidence of competition and a Narcissus effect. Evolutionary Ecology 6: $45-55$

Moulton MP and Pimm SL (1986) The extent of competition in shaping an introduced avifauna. In: Diamond $\mathbf{J}$ and Case TJ (eds) Community Ecology, Harper and Row, New York, New York, USA

Moulton MP, Sanderson JG and Simberloff D (1996) Passeriform introductions to the Mascarenes (Indian ocean): an assessment of the role of competition. Écologie 27: 143-152

O'Neill RV, Turner SJ, Cullinam VI, Coffin DP, Cook T, Conley W, Brunt J, Thomas JM, Conley MR and Gosz J (1991) Multiple landscape scales: an intersite comparison. Landscape Ecology 5: 137-144

Peters RH (1983) The Ecological Implications of Body Size Cambridge University Press, Cambridge

Peterson GD, Allen CR and Holling CS (1998) Ecological resilience, biodiversity and scale. Ecosystems 1: 6-18

Pimm SL (1991) The Balance of Nature University of Chicago Press, Chicago, Illinois, USA

Raffaelli D, Hall S, Emes C and Manly B (2000) Constraints on body size distributions: an experimental approach using a small-scale system. Oecologia 122: 389-398

Restrepo C, Renjifo LM and Marples P (1997) Frugivorous birds in fragmented neotropical montane forests: landscape pattern and body mass distribution. In: Laurance WF and Bierregaard RO (eds) Tropical Forest Remnants: Ecology, Management and Conservation of Fragmented Communities pp 171-189. University of Chicago Press, Chicago, Illinois, USA

Robertson WB Jr and Woolfenden GE (1992) Florida Bird Species, Florida Ornithological Society Special Publication 6, $260 \mathrm{pp}$

SAS Institute Inc. (1989) SAS/STAT User's Guide, Version 6, 4th ed Sas Institute Inc., Cary, North Carolina, USA

Silverman BW (1981) Using kernel density estimates to investigate multimodality. Journal of the Royal Statistical Society 43: 97-99

Smallwood KS (1994) Site invasibility by exotic birds and animals. Biological Conservation 69: 251-259

Stevenson HM and Anderson BH (1994) The Birdlife of Florida, University Press of Florida, Gainesville, Florida, USA, $892 \mathrm{pp}$

Veltman CJ, Nee S and Crawley MJ (1996) Correlates of introduction success in exotic New Zealand birds. American Naturalist 147: 542-557 